Article

\title{
Towards a Sustainability Assessment Model for Urban Public Space Renewable Energy Infrastructure
}

\author{
Kaan Ozgun (1)
}

School of Design, Queensland University of Technology, Brisbane 4000, Australia; kaanozgun@gmail.com

Received: 22 May 2020; Accepted: 30 June 2020; Published: 3 July 2020

\begin{abstract}
As cities develop new interventions for climate change mitigation, incorporating renewable energy in urban public spaces becomes a common norm to address sustainability objectives. However, current built projects and assessment practices mainly uses a "techno-fixes" approach focusing on strategies that are related to the environmental benefits and neglecting other potential strategies instigating social and economic benefits of renewable energy. The purpose of this study is to present a potential sustainability assessment model introducing new strategies for public space renewable energy use where social and economic benefits of renewables become evident. Supplemented with theories and principles from ecology, the model's economic strategies refer whether the project considers meaningful part of the produced electricity for generating a local economy; environmental strategy comprises embodied energy, energy storage and self-maintenance; social strategy includes whether the project considers generating active and passive interaction using on-site electricity. Ballast Point Park in Sydney was used as a test bed to examine the model and sustainability of park's renewable energy use. The findings showed that environmental strategies were evident in the park, social strategies remained average and economic strategies with renewable energy were lacking. Interactions with on-site produced electricity was further claimed to be an imperative feature of any public space. Recommendations were made specific to operational and planning impacts of the integrated model.
\end{abstract}

Keywords: renewable electricity distribution for public space; sustainability assessment model; integrated assessment for public space; tripartite altruism; urban renewable energy; ecological infrastructures

\section{Introduction}

Energy autonomy is an emerging trend at city, neighborhood, community and building scales. Renewable energy, distributed generation, transition from alternative circuit to direct circuit infrastructure and resilient micro and smart grids, all indicate a transition to new energy environments [1]. Using renewable energy in built environment becomes a common solution for climate change mitigation. However, its current use into urban environments is problematic from a sustainability perspective. Despite some exceptions, most built interventions concentrate on improving cities' environmental sustainability by retrofitting urban environments with technological additions such as green walls and photovoltaic panels [2]. Rather than perceiving renewable energy applications as crude technological addition that simply address the environmental sustainability objective of a sustainable top-down developmental approach, scholars and practitioners need to treat renewable energy as "ecological infrastructures". For example, positioning the location of "energy-ecology-society relations in a 'commons' space" and for a focus on techniques and social arrangements can serve the aims of sustainability and equity [3]. Public space showcases for the renewable energy commons approach, a bridge that connects mainstream energy with the emerging alternative decentralized energy movements. Public space can also be designed as a real living demonstration of what can be achieved in renewable energy. 
The success of sustainable development depends on several effective energy programs and their management strategies. This includes energy innovations; raising awareness through public and professional organizations; informing users about energy use and renewable types; increasing environmental knowledge through training and education; encouraging renewable energy use through finance, tax initiatives, and/or policies; and integrating assessment and auditing tools [4]. Because the concept of sustainability has evolved, scholars have recognized the importance of a multidisciplinary approach to the study and practice of sustainability. "The disciplines are essential for quality control" [5]. Each discipline creates its own quality control tools, one of which is the assessment of sustainability.

Tools that have been highly effective in pushing architectural industry to a better sustainability standard and have, by association, also influenced sustainable Landscape Architecture. The most appropriate ones concomitant to the scope of this study comprise 'LEED' (Leadership in Energy and Environmental Design) and 'SITES' (Sustainable Sites Initiative-a tool specifically for public open space assessment) in the USA, 'BREEAM' (Building Research Establishment Environmental Assessment Method) in the UK and 'Greenstar' in Australia.

SITES—which was jointly developed by the Lady Bird Johnson Wildflower Center at The University of Texas (Austin), the United States Botanic Gardens and the American Society of Landscape Architects-incorporates ecosystems services into its agenda aiming to foster sustainable land development and management practices [6]. While SITES aims to "create guidelines and performance benchmarks for sustainable design, construction and maintenance in Landscape Architecture projects" [6], it has not yet gained acceptance by the Landscape Architecture profession in Australia as a sustainability assessment tool for public spaces.

While renewable energy assessment is an important aspect of the SITES, their point rating scheme assesses public spaces based on a set of criteria focusing on environmental objectives such as making clean electricity available, promoting energy efficiency and reducing carbon footprint. For example, in their recently updated assessment guidelines (SITES v2), renewable energy is credited as "use renewable energy sources for landscape electricity needs" [7]. More specifically, if a project addresses fifty percent of annual outdoor site electricity, three points are scored. If a project generates one hundred percent of annual outdoor site electricity, four points are scored. Their description clearly states that renewable energy in a public space context currently does not count as a potential social sustainability initiator, but mainly considers the economic and environmental aspect of renewable energy and electricity production. While the relevant information in the guideline booklet includes a section about community renewable energy systems, its focus is on the produced electricity leasehold and management [7]. The current SITES v2 guidelines neglect the economic and social sustainability of on-site produced electricity and overlook renewable energy interactions from a public space context, thus misses the potential for enriching public space programs with new ways of public engagement.

Both theory and practice currently lack a sound knowledge base. Thus, the study formulates the following research question-which theories, principles and strategies can better contribute to the renewable energy-embedded public space and to what extent these principles can be used to form a potential assessment tool? With the advancement of renewable energy technologies and their increasing production capacities, renewable energy within a public space context can offer invaluable outcomes beyond the accepted environmental benefits. The purpose of this study is thus, to present a potential sustainability assessment model that realizes novel strategies instigating social and economic benefits of on-site produced electricity on top of the commonly accepted environmental benefits.

The optimal electricity distribution (OED) framework and its strategies were adapted and tested by assessing renewable energy projects designed for the Freshkills Park site in New York City [8]. A selection committee and multidisciplinary experts from the Land Art Generator Initiative (LAGI) design competition assessed and shortlisted twenty-five speculative projects [8]. This study considers LAGI as an authority in this emerging topic because LAGI organizes design competitions since 2010 and has gathered an archive of speculative projects over four different countries attracting experts, designers, and artists who work on the verge of science, art and technology. Therefore, LAGI's design 
proposals are likely to be indicative of some dominant contemporary approaches to the design of renewable energy-embedded public spaces. Part of the strategies presented in this study have been regularly used by the organizers in the last decade as criteria for judging schemes submitted to the LAGI design competitions. Both author's previous studies—as well as LAGI's frequently tested judging criteria-lay the groundwork for presented strategies in this study [8,9].

Because the SITES assessment framework is still in its development phase, the study's another objective is to enrich the scope of current assessment tools advocating creative processes and strategies that augment the sustainability of public space renewable energy. Contrary to the focus on the LAGI's speculative projects [8], this study adapts the OED framework and its strategies for assessing a built project site. Ballast Point Park (BPP) in Sydney is used as a test bed to demonstrate the model's performance and compatibility of its strategies.

To find out how each strategy is addressed in the design and how BPP design addresses sustainability from a public space renewable energy distribution perspective, the study acquires data from site observation, user survey and semi-structured interviews with consulted experts and designers. The following strategies are formulated coming out of author's earlier works and the LAGI's speculative project assessment criteria [8,9].

- Strategies under economic benefits involve selling $1 / 3$ or meaningful portion of the produced on-site electricity to city grid for generating income to the public space and its local community;

- Strategies under environmental benefits include using $1 / 3$ or meaningful portion of produced on-site electricity in the life time of renewable energy infrastructure for embodied energy, energy storage and maintenance of the renewable energy infrastructure and/or public space;

- Strategies under social benefits focus on the remaining portion of the onsite electricity to be used in creating activities whether the design considers social active and/or passive engagement with public space renewable energy.

Strategies are further substantiated with theories from ecology and described in the result section. The findings enable a blueprint for other sustainability practitioners who consider using renewable energy in their projects elsewhere. The study discusses the operations and planning impact of the potential assessment model and concludes with the limitations and future research. Recommendations are made how renewable energy can be effectively incorporated into public space. Local energy trading [10] and interaction with on-site produced electricity are further claimed to be an imperative feature for future public space designs. The need for an integrated approach when using renewables in public spaces is also discussed.

Next section first introduces the case then presents the methods of the study.

\section{Material and Methods}

This study used BPP as an "instrumental case" to comprehend an emerging paradigm, assessment of public space renewable energy infrastructure [11]. BPP was chosen as a case study because the park was recognized and awarded by the Australian Institute of Landscape Architecture (AILA) for its environmental sustainability innovations [12]. The park also represented the first Landscape Architecture project in Australia that incorporated renewable energy into its design. As presented in Figure 1, the 2.6 ha park was designed as a vegetated headland that retained its industrial footprint and opened to public in 2009 [13].

Mixed methods including semi-structured interviews with experts and designers, site observation and user survey were employed to investigate BPP. Five people in total were interviewed via Skype and in person. Three landscape architects from the leading firms involved in the design and planning of the park; one community expert and one project manager from a government authority responsible for the Sydney Harbor Foreshore parks engaged in project control and supervision.

Interviews were lasted between one to two hours. The model's strategies navigated the recorded interviews when analyzed using the NVivo software. The recordings were later transcribed as an 
intelligent verbatim [14]. The interview questions addressed the following topics; the essence of sustainability, triple-bottom-line (TBL), how renewable energy was integrated into the park design, and the original goals of overall design concerning social, economic, environmental and esthetic benefits.

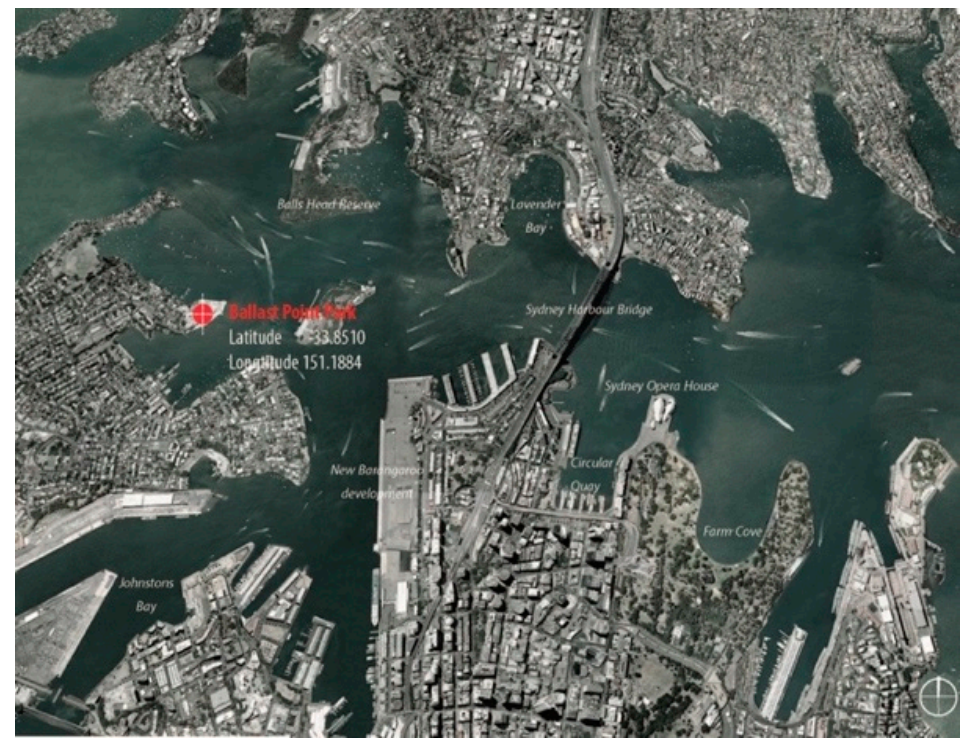

(a)

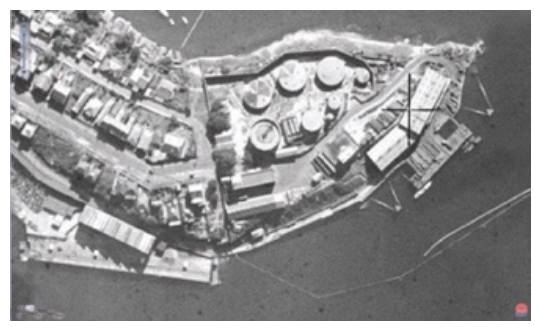

(b)

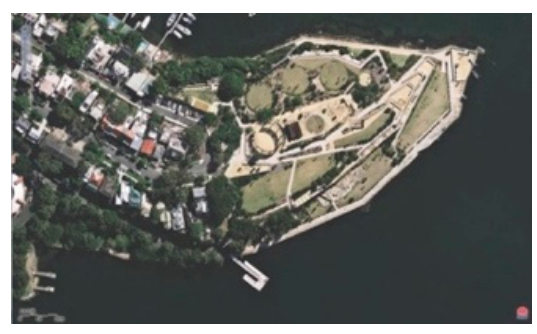

(c)

Figure 1. (a) Ballast Point Park (BPP) location map illustrates the Sydney Harbor context, map extracted from Google Earth; (b) 1943 BPP site; (c) 2010 BPP site, maps extracted from maps.six.ns.gov.au.

Site observation was used to understand the extend of activities concerning renewable energy infrastructure in the park. These included how renewable energy was incorporated into the design and how people interacted. The number of people using the specific location of the renewable energy infrastructure was also questioned against the use of other park functions. The observation was conducted during a two-week period in January 2014 including, weekdays, weekends and a public holiday when the summer started in the southern hemisphere. The site was divided into six zones and seven exposed spots were investigated, respectively to conduct the observations. By moving every twenty minutes from one spot to another "with rotating shifts of early morning 7:30-10:00 a.m.; morning 10:00 a.m.-12:00 p.m.; midday 12:00 p.m.-2:00 p.m., early afternoon 2 p.m.-4 p.m.; and late afternoon 4 p.m.-7 p.m.", park program was recorded and documented at each observation spot [14].

The type of renewable energy used in the design was vertical micro wind turbine, eight of which were integrated into a recycled steel construction in Figure 2 and erected at the park center as a renewable energy sculpture where the former tank 101 was standing.

Since wind was the primary renewable source in the project, wind intensity was measured using an anemometer from seven observations zones to understand if turbine locations associated with the site wind potentials [14].

To comprehend the social aspect of the model, thirty-four users at various locations were approached randomly during the site observation. A small survey was conducted asking two questions addressing if they reside near the vicinity and noticed the park's capacity for renewable electricity production. The outcome of the survey informed a better understanding of park's local or regional user group against their awareness about the park's renewable energy aspect [14].

Micro wind turbines technical specification notes and one interviewee's energy calculations were used to inform the turbines' life cycle and energy payback time which helped to recognize environmental strategies of the model. 


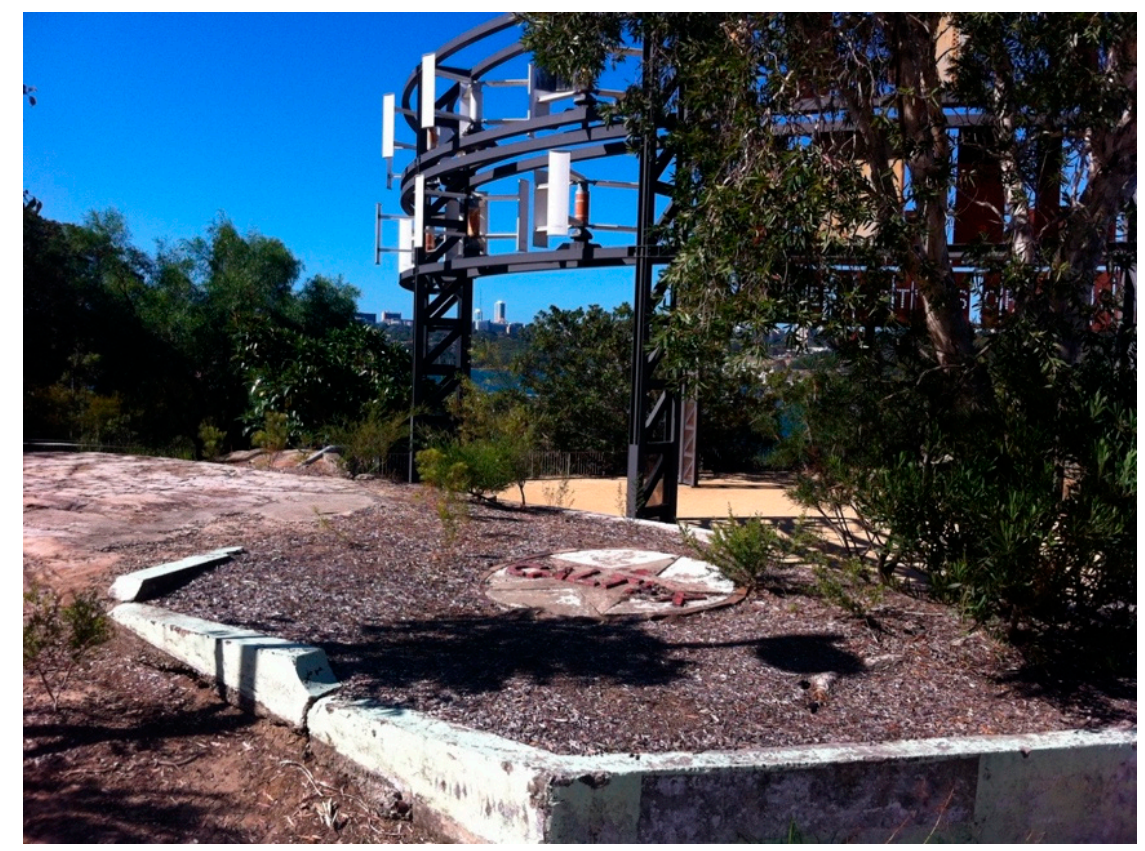

Figure 2. Renewable energy sculpture incorporated eight micro wind turbines was made from the former tank 101 recycled steel structures. Image by the author.

\section{Results}

Copious amount of sustainability assessment tools are used for different human environments, ones specific to landscape architecture profession are inadequate. While the effectiveness and leadership of assessment tools are key to energy future, current tools including the 'SITE', disregards a comprehensive sustainability assessment of public space on-site renewable electricity.

Next section presents theories and principals from ecology substantiating the strategies of potential assessment model, its components—and finally, its performance and outcomes after tested against the case study.

\subsection{Theories behind the Potential Assessment Model: The Link between Energy, Information and Public Space}

To provide food, water and shelter and to improve the quality of our life, energy is required. Energy comes in many forms, and the science of thermodynamics assesses energy transfers and transformations in processes, systems and devices. Two laws in principle rules the nature of energy. According to the first law of thermodynamics, energy cannot be extinguished or created and only its state can be altered and kept. The second law of thermodynamics can be defined within these states. Respectively, when the state of useful energy, the work capacity, a.k.a., 'exergy' dissipates, the state of disorder, a.k.a., 'entropy' arises [15].

Howard T. Odum, a renowned 20th century ecologist, introduced the ecosystem concepts of energy hierarchy and energy flow to the human environment. His early ideas on energy and nature stem from a provisional hypothesis - 'tripartite altruism' which was later developed to 'emergy' concept, a.k.a., 'the quality of energy' [16]. Emergy refers to the history of the system and the time and processes that have contributed to its current state [17]. The letters 'em' of emergy represents 'energy memory' and relate directly to the now more common term 'embodied energy'.

Odum's energy-nature equation so-called 'tripartite altruism' postulates that organisms in nature uses their energy based on $1 / 3$ ratio comprising higher order, lower order and, maintenance and storage purposes. He presented this theory using rabbits as an example illustrated in Figure 3. According to this theory, "They eat grass to live, grow and reproduce. Their manure fertilizes the grass that feed[s] them and they 'sacrifice' weak rabbits to predators to keep the population fit and in balance" [18]. 


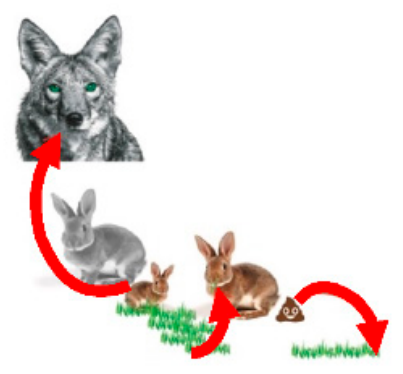

Figure 3. 'tripartite altruism' represented in rabbit's lifecycle.

Such formula can be useful when the public space is purposed to be designed toward an ecological sophistication. Particularly, Tripartite altruism's higher order, lower order and storage and maintenance strategy is simply about distributing the available energy on the system equally between three types of needs.

This study claims that active and passive interaction with renewable energy is an imperative feature of public spaces to establish a give-and-take connection between society and energy and to reach an evocative and assessable mode of sustainability. Similarly, the maximum empower principle also known as the Odum's fourth law states that during the self-organization process, systems advance interactions, processes and parts that amplify efficiency and production [19-21]. Odum's fifth law further asserts that "system processes maximize power by interacting abundant energy forms with ones of small quantity, but a larger amplification ability" [19]. Thus, design processes and outcomes targeting an ecological sophistication in public space can be used as a tool to educate the public about a sustainable energy lifestyle and to increase general environmental awareness, so maximizes energy efficiency and production in the broader community, leading to long-term benefits.

Focusing on the social aspect of public space where people mingle through communication, interaction and learning from their surroundings and from each other, Miller [22] argues "[p]ublic spaces do not exist as static physical entities, but are constellations of ideas, actions and environments". Therefore, public space can shift society into a sustainable energy lifestyle when used as an educational and information platform. When conceptualized as a self-organizing state, public space can become, in Odum's terms, "a platform to create useful information for community", in doing so, endorse a larger commitment to sustainable energy across multiple social realms.

\subsection{The Potential Assessment Model: Components}

Theories explained in the previous section substantiate a set of strategies for the assessment model to assess the sustainability of renewable energy infrastructure in BPP. While author's previous study focused on the OED framework's $1 / 3$ ratio as a rigid constraint for scoring, this study slightly modifies wording for a real built case and proposes a flexible, but meaningful distribution of produced renewable electricity. In other words, a project can fulfil electricity distribution not equally in a quantitative sense, but still distribute electricity between social, economic and environmental strategies while the outcome can be more synergistic and transcends a quantitatively balanced approach.

Accordingly,

- Economic strategy refers to using one third or meaningful part of the on-site produced electricity to be sold to city grid for generating income to the public space and its local community;

- Environmental strategy suggests whether the design considers embodied energy, energy storage and maintenance of the renewable energy infrastructure and/or public space. That is, one third or meaningful part of the produced total electricity throughout the life time of renewable energy infrastructure needs to pay back its maintenance cost and embodied energy considering its depreciation value; 
- The model's final one third or meaningful part of the produced electricity focuses on creating social strategies using on-site renewable energy. That is whether the design considers any active and/or passive engagement using public space renewable energy.

More precisely, the economic strategy is quantified by using a scale from zero to four points. Since each case study site would have different energy distribution needs, appropriateness of the distribution strategy would score the highest point. The project scores zero point if no generated electricity within public space is used for local energy trading. The project scores one point if designers are aware of and have the intention to implement the model's economic strategy however project fails to do so for several reasons as some of them are exemplified and presented in this case study. If the strategy is implemented, but unmeasured and unmonitored the project scores one and a half points. A project scores two points if total production capacity is used for local energy trading [10]. A project scores three points if environmental or social strategy is considered in addition to economic engagement. A project scores three and a half points both environmental and social strategies are considered in addition to the economic strategy. A project scores four points if full generated electricity amount is equally and/or meaningfully distributed between three assessment strategies.

To comply with the environmental strategy, the project shall consider embodied energy, energy storage and contributes to the maintenance of the infrastructure and/or the public space. A project scores zero point, either designers are not aware or consider any above factors. A project scores one point if an intention for addressing all three factors of environmental strategy is clear however project fails to achieve this. If an intention for addressing two of the three factors is obvious, the score would be $2 / 3$ point. If an intention for addressing at least one of the three factors is apparent, the score would be $1 / 3$ point. A project scores two points, if successfully and fully addresses one of the three factors. A project scores three points, if any two factors are fully addressed. A project scores four points, if all three factors are considered simultaneously.

The model's social strategy assesses whether public space renewable energy generates both active and passive engagement with public. Educational, informative and place making activities can involve active and/or passive engagement with on-site renewable energy. Here active and passive engagement is twofold.

The first one is about using on-site renewable electricity through either production or consumption activity within public space. An example of active renewable electricity production is Piezoelectric generator. Active renewable electricity consumption activities comprise mobile phone charge, car battery charge, using electricity for street performance while passive renewable energy consumption may include digital information screens where users consume electricity in an indirect manner.

The second one refers to 'energy quality' concept introduced earlier in the theory section which is literally about 'quality design' or quality of the renewable energy infrastructure. More specifically, how the design communicates with public, what diverse uses intentionally and unintentionally present, observable or hidden. Active engagement with renewable energy may include a meta sustainability narrative the design is trying to communicate regardless of functioning as a renewable electricity generator. Interpretative signage of renewable energy may be incorporated into the design to communicate with public at a symbolic level. Whereas, passive engagement involves spontaneous public space activities, for example the design is used as a backdrop for market stall installation, photography and performances. Or the design triggers questions in public about its function, evokes several other meanings and promote multifunctionality.

Respectively, a project scores zero point, if renewable energy design does not generate any engagement with public whatsoever. A project scores one point if any intention creating either active or passive interaction is apparent, but the project is failed. A project scores two points if any intention creating both active and passive interaction is obvious, but the project is failed. A project scores three points, if either active or passive engagement is considered. A project scores four points, if both active and passive engagements using on-site renewable energy are considered. Points in each segment 
would be divided into two-one covers using on-site renewable electricity and other one concerns with parameters related to design quality of the renewable energy infrastructure.

Table 1 in the following section presents the assessment scoring in detail while incorporating information from this prescribed text.

Table 1. Ballast Point Park renewable energy infrastructure sustainability assessment scores.

\begin{tabular}{|c|c|c|c|c|c|}
\hline & & $\begin{array}{c}\text { Economic } \\
\text { Assessment Score (4) }\end{array}$ & $\begin{array}{c}\text { Environmental } \\
\text { Assessment Score (4) }\end{array}$ & $\begin{array}{l}\text { Social Assessment } \\
\text { Score (4) }\end{array}$ & $\begin{array}{l}\text { Top Assessment } \\
\text { Score (12) }\end{array}$ \\
\hline \multicolumn{6}{|c|}{ Sustainability Strategies } \\
\hline Economic & -Local energy trading [10] & 1 & $\mathrm{n} / \mathrm{a}$ & $\mathrm{n} / \mathrm{a}$ & 1 \\
\hline \multirow{2}{*}{ Environmental } & -Embodied energy & $\mathrm{n} / \mathrm{a}$ & 2 & $\mathrm{n} / \mathrm{a}$ & \multirow[b]{2}{*}{2.7} \\
\hline & -Energy storage & $\mathrm{n} / \mathrm{a}$ & $1 / 3$ & $\mathrm{n} / \mathrm{a}$ & \\
\hline Social & $\begin{array}{l}\text {-Passive interaction modes } \\
\text { with renewable infrastructure }\end{array}$ & $\mathrm{n} / \mathrm{a}$ & $\mathrm{n} / \mathrm{a}$ & 2 & \multirow[t]{2}{*}{4} \\
\hline Strategy & $\begin{array}{l}\text {-Active interaction modes } \\
\text { with renewable infrastructure }\end{array}$ & $\mathrm{n} / \mathrm{a}$ & $\mathrm{n} / \mathrm{a}$ & 2 & \\
\hline
\end{tabular}

Economic Sustainability Strategy—Local Energy Trading *

(0) No local electricity trading

(1) Designer's intention exists, however project fails

(2) All generated electricity used for local trading

(3) Part of the generated electricity used for social and environmental strategies **

(4) All generated electricity distributed equally/meaningfully between each strategy

Environmental Sustainability Strategy-Embodied Energy/Energy Storage/Self Maintenance ***

(0) None

(1) Designer's intention exists; however, project fails ****

(2) If project successfully and fully addresses one of the three factors.

(3) If any two factors are fully addressed.

(4) A project scored four points, if all three factors are considered simultaneously.

Social Sustainability Strategy_Active/Passive Engagement with on-site renewable energy ^

(0) None

(1) Designer's intention exists for Active or Passive engagement through direct electricity consumption ${ }^{\wedge}$ or Production ${ }^{\wedge}$, however project fails to do so.

(2) Designer's intention exists for Active and Passive engagement through direct electricity consumption or production; however, project fails to do so.

(3) If project fulfils active or passive engagement using on-site renewable electricity.

(4) If project fulfils both active and passive engagements using on-site renewable electricity.

${ }^{*}$ If the strategy is implemented, but unmeasured and unmonitored, the project scores one and a half points; ${ }^{* *}$ While social and environmental strategy scores (1) point, each strategy scores (1/2) point; ${ }^{* * *}$ Self maintenance factor is about the maintenance of energy infrastructure or/and public space, this includes primary electricity demand for permanent functions in public space such as lighting, heating, energy storage, bikeshare, electricity for pump, irrigation, etc.; ${ }^{* * *}$ Each three factors will get $1 / 3$ of the score if considered in the design, but fails; ${ }^{`}$ Educational, informative and place making activities can cover active and/or passive engagement with on-site renewable energy; $\sim$ Points in each segment would be divided into two-one covers using on-site renewable electricity and other one concerns with parameters related to the design quality of renewable energy infrastructure. ^ Active electricity consumption for public space users such as mobile phone charge, wireless use, car battery charge, etc. whereas passive electricity consumption for example digital information screens ${ }^{\wedge}$ For example, Piezoelectric generator produces on-site electricity.

\subsection{The Proposed Assessment Model: Performance and Outcomes}

Table 1 illustrates economic, environmental and social strategies against assessment scores for the BPP renewable energy infrastructure. The highest score for renewable energy infrastructure assessment is calculated as twelve points. BPP scores a total of seven point seven from twelve points which approximates a success rate of sixty-four percent.

\subsubsection{Ballast Point Park Renewable Energy Infrastructure Economic Sustainability Assessment}

- Renewable energy's economic benefit was an incentive to include the concept in the park; however, the integrated wind turbines did not function and did not generate any electricity [14,23-25]. 
While BPP was a well-regarded project that fulfilled many sustainability aspects, specific to local economy of the park, little information was found. Minor activities in the park such as wedding ceremonies support park's local economy and a recent study has revealed a value increase over fifty percent on surrounding properties since the park opened to public in 2009 [14,26].

Economic benefit from on-site generated electricity was initially planned to balance out the operational cost of the park, however micro wind turbines installed did not operate as anticipated [14,23-25]. Annual wind data were not incorporated into the process of decision making since no calculations were done by renewable energy consultant. Wind turbines' technical specification notes were used as the only primary source to predict possible yield. However, to anticipate the wind turbines' possible location, local wind measurements were needed which were never realized [23]. Following upon this gap, also to better understand reasons behind the dysfunctional wind turbines, wind measurements were taken by using an anemometer at seven different observation locations during site trips as presented in Figure 4a.

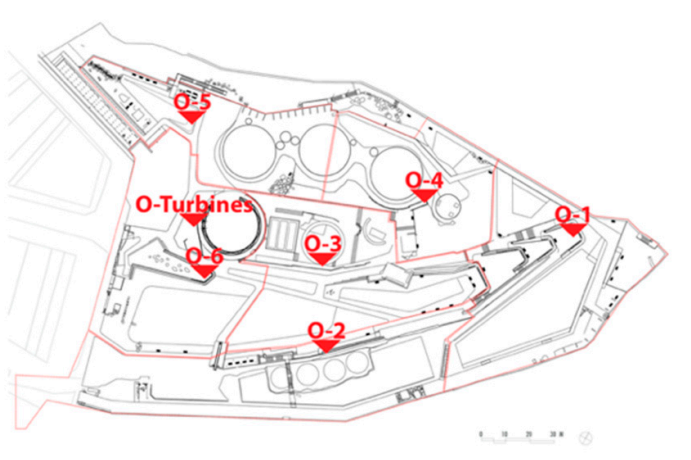

(a)

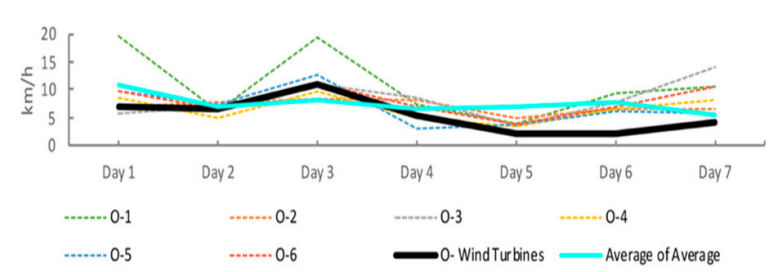

(b)

Figure 4. (a) BPP location map showing observation spots; (b) graph showing the daily averaged wind values for each spot.

During regular visits for two weeks in January 2014, no spinning movement was monitored on any single wind turbine despite seeing the park at some extremely windy days.

Figure $4 \mathrm{~b}$ presents a graph showing daily averaged wind values for each spot, respectively while Table 2 demonstrates each zone's average wind values during one week period. Each value in Table 2 represents daily average wind speed calculated from 7:30 a.m. to 7 p.m. by moving every twenty minutes from one observation location to another. Black thick line in Figure $4 \mathrm{~b}$ represents the turbines' average wind speed at their exact location where wind values repeatedly stayed below the other measured average wind speeds. While local wind measurements are crucial to determine the turbines' exact location, the economy of generated electricity requires yearly wind data since every wind turbines including very successful ones show strong seasonality in its output. Therefore, data presented in Table 2 is indicative for a general understanding of site wind potentials and so possible ideal locations of the turbines.

According to the model's economic sustainability assessment, BPP scored one from four points. In this study, local electricity production's economic value was an essential strategy for sustainable renewable energy-embedded public spaces and BPP has failed to do so. BPP has accomplished critical success in its own right and has deservedly won many awards for addressing numerous environmental sustainability criteria, but in the context and for the purpose of this study,-when assessed against the more thorough renewable energy economy potential which the proposed model shows here-it fell short.

More specifically, the model indicated an equation using $1 / 3$ or meaningful amount of the produced electricity for local energy trading which could bring income to the community. However, at the time, the technology was new and underdeveloped. Generated electricity was not efficient for providing 
enough economic incentive [23-25]. Such shortcoming was also discussed later as one limitation of the model. Presumably, past technologies would not able to address this strategy fully, therefore for the time being, designer intentions are invaluable to understand whether this strategy originally included in the project's agenda.

Table 2. BPP daily local and average wind values.

\begin{tabular}{ccccccccc}
\hline Date & $\mathbf{O - 1}$ & $\mathbf{O - 2}$ & $\mathbf{O}-\mathbf{3}$ & $\mathbf{O - 4}$ & $\mathbf{O}-\mathbf{5}$ & $\mathbf{O}-\mathbf{6}$ & $\mathbf{O - W i n d ~ T u r b i n e s}$ & Average of Average \\
\hline Day 1 & 19.7 & 7.1 & 5.6 & 8.5 & 9.6 & 9.8 & 7.1 & 10.9 \\
Day 2 & 6 & 7.6 & 6.9 & 4.8 & 7.4 & 6.5 & 6.4 & 7.1 \\
Day 3 & 19.3 & 8.4 & 10.8 & 9.7 & 12.7 & 11.2 & 11 & 8.2 \\
Day 4 & 7.4 & 8 & 8.6 & 4.9 & 3 & 7.1 & 5.2 & 6.6 \\
Day 5 & 3.9 & 4.9 & 3.5 & 3.4 & 3.9 & 3.8 & 2.1 & 7.0 \\
Day 6 & 9.5 & 6.7 & 7.8 & 6.7 & 6.3 & 6.8 & 2.1 & 7.9 \\
Day 7 & 10.4 & 6.7 & 14.1 & 8.1 & 5.9 & 10.4 & 4.3 & 5.5 \\
\hline Average & 10.9 & 7.1 & 8.2 & 6.6 & 7.0 & 7.9 & 5.5 & 7.6 \\
\hline \multicolumn{7}{c}{ O-N: observation location. }
\end{tabular}

\subsubsection{Ballast Point Park Renewable Energy Infrastructure Environmental Sustainability Assessment}

According to the model's environmental assessment, BPP shall consider embodied energy, energy storage and the maintenance of the infrastructure and/or park successfully.

- The park's 'cradle-to-cradle' (CTC) design philosophy favorites embodied energy consideration of the renewable energy infrastructure.

- Wind turbines and batteries are part of the renewable energy infrastructure, however none of them functioned and delivered the anticipated energy yield.

- Public space maintenance using on-site renewable electricity was discussed by interviewees however never become a reality.

What was interesting about embodied energy aspect of the BPP renewable energy infrastructure was the 101 oil tank and its recycled steel frames repurposed as a renewable energy sculpture on the basis of park's post-industrial history. However, no life cycle analysis done; designers applied the 'cradle-to-cradle' (CTC) philosophy to the park's overall design at multiple scales indicating a focus on environmental sustainability for design decisions. According to the model, embodied energy prevails important implications for renewable energy devices. Embodied energy of a renewable energy infrastructure refers to 'energy pay back times' (EPT); in other words, the energy and revenue spent on a renewable energy device until constructed and functioning [27-29].

Commenting on EPT, one interviewee presented his preliminary calculations referring to twenty-nine years pay-back time when eight micro wind turbines spin at $10 \mathrm{~m} / \mathrm{s}(36 \mathrm{~km} / \mathrm{h}$-Force 5 fresh breeze). The wind turbines catalog used in the project specified each turbine generating $800 \mathrm{~W}$ at $14 \mathrm{~m} / \mathrm{s}$ [23]. Considering the latest developments in renewable energy technology, EPT has significantly dropped nowadays in comparison to eight years ago. Thus, despite the limitations of past technological shortcomings, designers were aware of the topic and considered embodied energy. In the case of BPP, the CTC design philosophy was applied to the design of energy sculpture. When assessed by the proposed model, the CTC approach taken by designers addressed embodied energy, which scored two from four points and partly fulfilled the model's environmental strategy. Designers used pre-existing structures and materials from the site during the construction phase, thus reduced the art piece's embodied energy cost.

Concerning wind turbines and energy storage, data from site observation and interviews revealed that neither batteries nor turbines functioned. Turbine moving segments have rusted over time because the sprayed sea salt prevented turbines spinning [25]. As originally calculated by the distributer, wind turbines' power would have sufficed park's energy need. However, to acquire full performance 
from the installed turbines, several criteria needed to be addressed. For example, determining the most productive wind harvesting location was a crucial strategy to be fulfilled which was not implemented. Therefore, the project scored $1 / 3$ point partially addressing this strategy.

What stood out from an environmental assessment of the relation between maintenance and renewable energy infrastructure, designers intended to use generated electricity from the renewables for reducing park maintenance costs. However, because any technical and expert knowledge was lacking, the renewable energy devices did not function as intended, and did not meet the goal of supplying electricity to the park for daily use [23-25]. Thus, the park did not generate electricity for itself or the community, and thereby neglected both economic and partially environmental (self-maintenance) aspect of on-site electricity production. From this finding, the project achieved a score of $1 / 3$ point. The environmental sum total was then calculated as 2.7 from 4 points.

\subsubsection{Ballast Point Park Renewable Energy Infrastructure Social Sustainability Assessment}

- No active and/or passive engagement with on-site renewable electricity was recorded on the site. This has also never become the designers' intention [23,25].

- Active engagement was generated through 'quality design'; powerful symbolic meaning from a former fossil fuel tank to a renewable energy sculpture; interpretive signage.

- Passive engagement was generated with renewable infrastructure through spontaneous use.

- Designer's esthetical concerns, community will and site wind exposure influenced the decision for using wind turbines in the design.

Throughout regular site visits over two weeks in January 2014, no spinning movement was monitored on any single wind turbine, owing to this, no active or passive engagement with on-site renewable energy was recorded. Moreover, designers did not intend creating activities in public space using on-site generated electricity $[23,25]$. However, transforming a former fossil fuel tank to a renewable energy sculpture conveyed a powerful symbolic meaning which was the main design intention. The principal designer emphasized his view on the societal impact of the designed renewable energy sculpture with his own words "the big fossil fuel tank turned into the biggest wind turbine thing on Sydney Harbor. There is poetry there" [14,25]. Such narrative was also reflected in using interpretive signages across the park as seen in Figure 5. In doing so, the project scored one point through addressing the 'quality design' strategy-active engagement side of renewable energy.

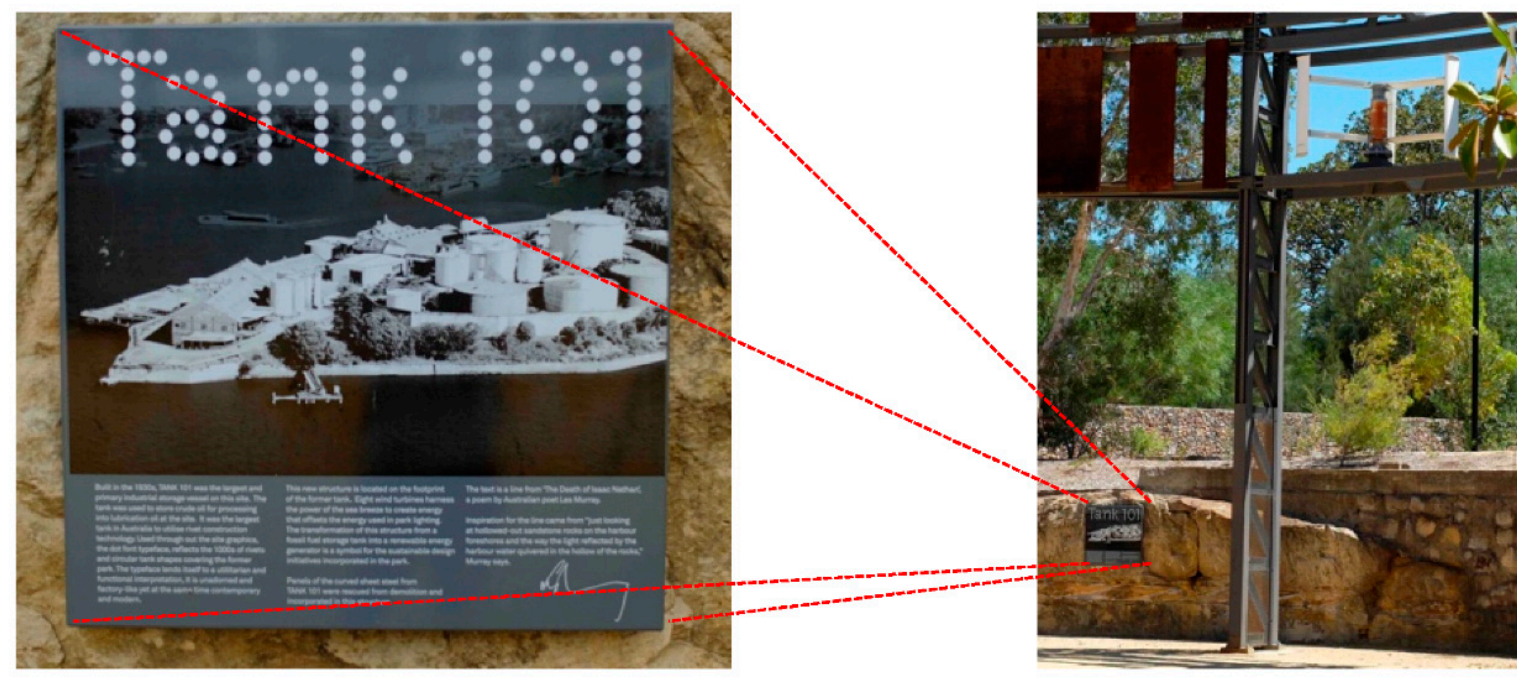

(a)

(b)

Figure 5. (a) The interpretive signage of renewable energy sculpture; (b) The renewable energy sculpture. Images by the author. 
The assessment of renewable energy passive interaction targeted design multifunctionality. Several monitored and recorded activities as well as anecdotes from public users provided ample data to score another point for assessment. For example, the renewable energy sculpture was used for wedding photography in Figure 6a and its structure was pinned with geo-tags at several locations in Figure $6 \mathrm{~b}$. Anecdotally, the sculpture together with some other park divisions were used as meeting points for parkour performers.

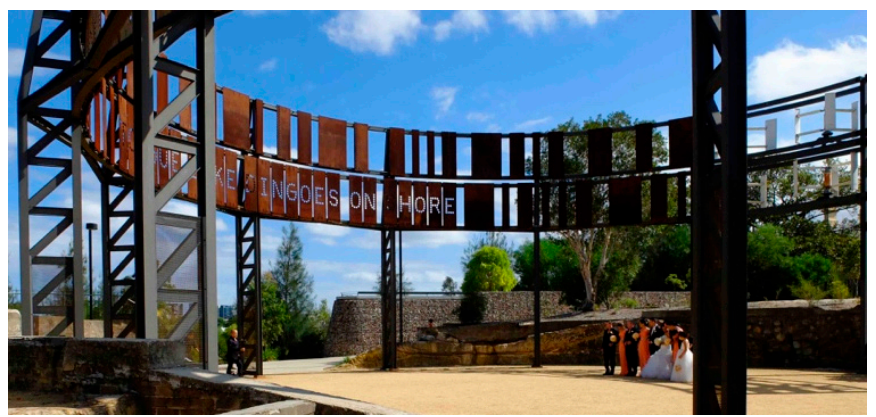

(a)

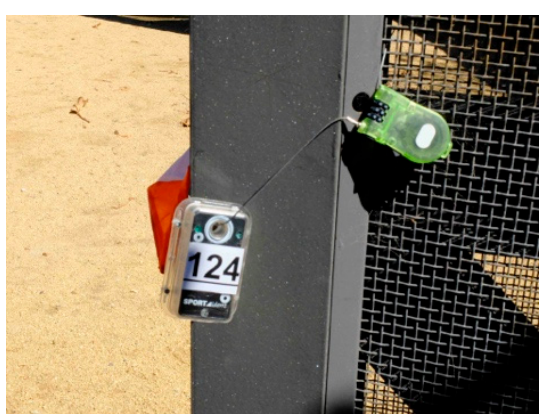

(b)

Figure 6. (a) Renewable energy sculpture used as a background for wedding photography; (b) geo-tags were pinned to the renewable energy sculpture. Images by the author.

During site visits, the survey presented in Figure 7 was completed with thirty-four participants. Only 24 percent of the park users were aware of the park's capacity to produce electricity, and these park users were living in the vicinity.

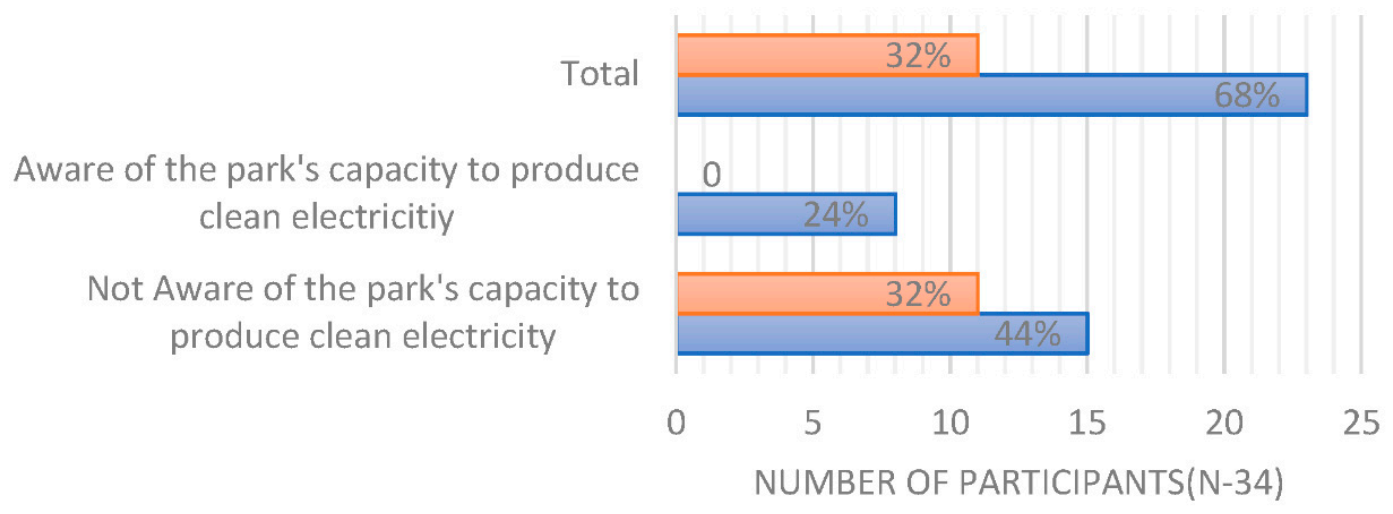

Do not live in the vicinity $\quad \square$ Live in the vicinity

Figure 7. Survey results revealing user's response to the park's renewable energy.

This finding was further elaborated with interview data for example using on-site produced electricity to encourage public space activities was never brought up in any community consultation process. However, during these meetings some initial ideas were seeded for example using the wind as a choice for renewable source and retaining the former oil tank on the site. As discussed with the principal designer, the idea of generating on-site electricity originated from the community and its stories about flying kites on the site because of strong wind exposure. The idea of keeping the former tank was originally suggested by community to be used as a landmark for captain's sense of direction while roaming in the harbor. These ideas together with designers' esthetical concerns further formed the final design which was developed in a design charette and the former tank turned into a renewable energy sculpture [25]. 
According to the assessment model, simply relying on the renewable energy's environmental and economic aspect was not sufficient to create genuinely sustainable renewable energy embedded public space. An important factor in accomplishing social outcomes of renewable energy use was its public acceptance [30,31]. For example, photovoltaic (PV) panels, despite their controversial esthetic qualities, needed to be visible to users to increase their social acceptance [32]. These esthetic concerns were reiterated in the case study that designers were hesitant to integrate PV panels into the BPP design [23]. Moreover, because most park users did not know the park had the capacity to produce electricity, the socially sustainable knowledge and acceptance of renewable energy was limited [14]. Therefore, some issues emerging from these findings were related specifically to the designers' priority of focusing on the esthetic and technological aspect of renewable energy, rather than on the potential socioeconomic relations stemming from its local production.

From a social sustainability viewpoint, BPP's renewable energy scored two points through active and passive engagement. Several aspects of which referred to 'quality design' - by definition design quality of the energy sculpture and its well-thought narrative, but not from on-site produced electricity as clearly presented in this section.

\section{Discussion}

Current sustainability assessment tools specific to the Landscape Architecture profession devalue public space renewable energy use by neglecting the potential social, economic and environmental engagements of local electricity production that could otherwise increase the sustainability of the public space. One common issue that emerges from the BPP case study findings as well as the reviewed literature is that although a broad range of sustainability assessment tools have been used for different human environments, ones specific to the Landscape Architecture profession are limited.

Therefore, for the purpose of this study, the SITES initiative is selected as a typical example which is a legitimate well-regarded sustainability assessment tool in the profession. As discussed, the sustainable SITES initiative assesses the sustainability of public spaces with a point-based system [7]. However, SITES' assessment approach to renewable energy-embedded public open spaces is one-sided, often misses the social and economic relations around electricity production and, thus, only ticking the environmental sustainability box. This may be because SITES' focus is only on the renewable energy devices, rather than on the activity of electricity production. The SITES' limitation to assess the renewable energy side of a public space led the development of a potential future assessment tool as presented through the BPP case in Sydney.

Having a device-based focus on renewable energy is symptomatic of a top-down sustainability development approach. A possible explanation for this may be ingrained in the definition of 'techno-fix', which holds that present market conditions generally satisfy demand with quick solutions to increase consumerism [33]. Respectively, urban renewable energy is widely framed as a technological addendum, an afterthought, by definition a retrofit to public space designs. Currently renewable energy infrastructures embedded in urban environments have a relatively small electricity production capacity. In addition, energy storage utilities are still expensive, and distributed energy infrastructure systems in cities around the world are not widespread. For the time being, existing industry practices may be reluctant to make use of producing clean electricity in cities at maximum potential. However, such parameters indicate only present day constraints and it is foreseeable that these constraints will be overcome in the very near future. Therefore, a balanced quantity between the proposed strategies may gain more credit if not now, but later.

The presented model promotes social, economic and environmental engagement using on-site renewable energy. For this reason, it requires negotiation among many stakeholders, including policy makers, local government, neighborhood residents, public space users, designers and experts involved in the project. It makes the design process more transparent and gives each stakeholder equal opportunity for management and/or involvement. It is likely, therefore, that designers can be more cognizant of the sustainability of renewable energy. This in turn, can reduce the propensity for 
superficial 'green wash' outcomes and increase the importance of social and economic factors involved in electricity production.

The model can be scaled for household and neighborhood uses. For example, researchers can identify how much clean electricity a household generates; sells to the city grid; uses for its own needs including maintenance, storage, ordering, installation, transportation, as well as its own embodied energy. The electricity's specific consumption also becomes the focus of some recent studies that investigates integrated solutions for households' peak energy demand [34]. The proposed model can guide a multidisciplinary research team in specifying the social, economic and environmental engagement strategies according to a household's energy needs. Simply put, a balance is needed between these three aspects. The model can also be used for long-term sustainable development to evaluate the efficacy of renewable energy investments for impoverished communities. It may also benefit energy independence studies for energy poverty alleviation in remote settlements [35].

The model's economic engagement strategy not only fosters a surplus to community but can indicate a green rating for the neighborhood. For example, some emerging distributed energy neighborhoods have energy information centers. Their main roles are marketing and advertising the engagement with renewable energy and promote sustainable energy education. These neighborhoods are widespread in some European countries such as Austria, Germany, Denmark, Sweden and the Netherlands [36-40]. Public spaces designs in line with the thinking promoted through the proposed model here can showcase its neighborhood electricity use as a public space amenity. A distributed energy market economy is reliant on smart grid systems, which require active interaction with its stakeholders [41]. Therefore, each public space design can support such interaction addressing site-specific social, environmental and economic data while integrating renewable energy technology to support a local energy economy, monitoring electricity production and consumption, and informing residents about their energy use, with a view to helping them to be more energy responsive. Urban administrative policies can then use such data to channel subsidies for energy responsive neighborhoods and encourage the transition to sustainable energy.

Another local energy trading application is so-called transactive energy which uses the existing infrastructure for renewable energy distribution. A real world example was tested through Monash Micro grid case study in Melbourne, Australia where a complete hardware and software infrastructure are staged for micro-grid energy management [10]. Furthermore, some alternative administrative tools are evolving to provide on-site energy services. For example, the sustainable energy utility (SEU) offers on-site energy services to empower private energy markets and facilitate self-finance for communities [42,43]. However, the presented model sheds new light on the community energy distribution using public space as a point of departure, it requires side information, policies and administrative innovation similar to the SEU for better integration within human environments.

The proposed model's environmental assessment strategy formed a significant connection between embodied energy, energy storage and maintenance of the infrastructure and/or park. The BPP designers seemed to be more aware of such connection, because environmental, social and economic strategies using renewable energy scored highest to lowest, respectively. In the previous study of the author, twenty-five speculative designs submitted to the LAGI design competition were assessed against very similar strategies whereas the findings revealed an entirely different outcome-the shortlisted projects' renewable energy based economic, environmental, and social strategies scored highest to lowest average, respectively [8]. This outcome perhaps suggests environmental interventions in general prevail dominant trend for the mainstream urban sustainability practices which is clearly the case as presented in this study. However, LAGI's philosophy on renewable energy and public space is highly responsive, their approach to the sustainability esthetics, as noted by Elizabeth Meyer, needs to be revisited. Meyer states that the esthetics of sustainable design need to be considered within two contexts-'appearance' and 'function' - to have a significant cultural and societal impact. She argues that 'function', also referred to as 'fitness' or 'performance', cannot be experienced through representation, but through direct engagement [44]. 
In this study, direct engagement with renewable energy-recognized as an important attribute of public spaces-was presented as active and passive interaction with renewable energy. 'Active interaction' referred to the direct consumption of produced electricity; for example, wireless services and energy charging points. 'Passive interaction', whereas, referred to the indirect consumption of the produced electricity, such as video artworks and interactive energy signage. Another dimension of active and passive interaction with renewable energy was 'quality design'. In other words, how designer intended to communicate with public about the renewable energy design in the first place. In BPP, active interaction was depicted through a successful meta-narrative, interpretive signages and use of renewables across the public space. Whereas, passive interaction involved spontaneous uses of the design concerning multifunctionality and so obliquely related to the renewable energy feature; fo example, using the structure as a backdrop for a street performance or photography exhibition.

In the light of the introduced theory, this study argued that such enhancements in our interactions with renewable energy in public space correlated with the observed tendencies of self-organized mature ecosystems. For example, Odum's fifth law of thermodynamics states that, "system processes maximize power by interacting abundant energy forms with ones of small quantity, but a larger amplification ability" [19]. Therefore, the more ecologically sustainable public space was the one that more effectively responded to the fifth law by engaging with renewable energy at the highest level of interaction, that was, through both active and passive means. The central premise here was that, the greater the number of active and passive interactions between renewable energy and public spaces, the greater the likelihood that renewable energy would influence society's sustainable energy lifestyle.

The presented model and its informed social strategies concern with public space engagement and place-making through renewable energy and its use in and around the public space. This use can be elaborated through site specificity, designer's approach and community wishes. Parallel urban trends are evident in the fields of media architecture, urban informatics and interactive media and public art, which can be used with generated on-site clean electricity for advancing the message of renewable energy.

\section{Conclusions}

This study investigated the link between renewable energy and public space and developed a potential integrated model to assess the sustainability of public space renewable energy infrastructure. The model was tested through assessing a renowned public space awarded for its environmental sustainability innovations. Since incorporating renewable energy use in urban public space is an emerging field, this study is built upon author's previous work on assessing sustainability of speculative designs in which findings revealed an imbalance for distributing onsite generated electricity from a public space context.

The devised model, strategies and related ecological theories are the key contribution of this study. Sustainability practitioners have not developed a full understanding of public space renewable energy use beyond it being a mere design retrofit. The presented strategies in Section 3.2 would be useful for designers to better incorporate renewable energy into their designs. Such strategies would also benefit public space assessment bodies such as the SITES initiative. Importantly, the link between three strategies in this study was argued to become indispensable for an ecologically sophisticated public space design.

Another crucial contribution is the acknowledgement of the importance of using generated electricity immediately within public spaces through active and passive interactions. An ecologically sophisticated public space design should be energy responsive in the sense that it increases the social, economic and environmental sustainability of its locale. At the same time, such a public space may generate useful information for the community, which can then be used as a basis for sustainable energy transition and social change. This claim stems from the "maximum power principle", which is considered as Odum's fourth law of thermodynamics. Odum's fifth law also posits that active and 
passive interactions are imperative for on-site renewable energy, and, respectively, the more these interactions occur in public spaces, the greater the chances the public space would help society transitioning to a sustainable energy life style.

Finally, the study presented the need for an integrated approach to renewable energy and public space, to achieve not only meaningful and measurable sustainability, but also to communicate the reciprocal relations between society and energy.

\subsection{Limitations}

The model's major limitation is the devised strategies and their appropriateness with the renewable energy project. While these strategies explicitly engage with renewable electricity at multi-level; site-specific features, designer's esthetical concerns, decisions on renewable energy technology types and many other unforeseen factors may influence full exploitation of renewable energy as presented through the BPP. From an overall sustainability perspective, BPP is successful on its own right. However, when the renewable aspect of the project is scrutinized, a different outcome becomes evident.

Another limitation of the study is time factor. Because the project examined was built in 2009, at the time renewable energy technologies were less efficient and economically infeasible considering its highly expensive manufacturing cost against lower production capacity. Therefore, in the past a design fully responsive to the proposed model' strategies in an urban condition was not practical and was perhaps impossible. This is why the project used the BPP as a test bed, merely to demonstrate the model's function rather than focusing on the project flaws.

\subsection{Future Research}

A natural progression of this study is to increase the built project case study sampling. In turn, this will increase the assessment model's generalizability. This study simply presents the first project from a wide range of potential sites elsewhere. Initially, the model and its production-oriented approach will be best applied to public open spaces, where local electricity production is used in neighborhoods to create a more sustainable community.

In the future, opportunities may arise to improvise other interactions with generated electricity. Until that time though, the balanced and/or meaningful distribution of renewable electricity generated in public space should be served as a blueprint as long as site factors permit. Such thinking presented here would enable designers engage with the project's renewable energy at the outset rather than considering it an afterthought. Conceptualizing the public space interactions and renewable energy simultaneously while targeting an equal and/or meaningful balance between social, economic and environmental strategies would draw an effective path for transitioning to a sustainable energy future.

Rapid technological advancements on renewable energy coupled with increasing rate of efficiency and decreasing costs would accelerate transforming our understanding of urban renewable energy from a technological addition into a community production activity. This shift in thinking should be first embraced by design and assessment practices to create a sustainable energy future. Cities around the world are gradually taking steps toward building new social, economic and political frameworks and infrastructures such as resilient micro and smart grids, virtual renewable energy utilities, sustainable energy utilities and distributed energy neighborhoods. The spatial and social adaptation of these technologies in cities is as critically important as is their technical capability.

Cities are in crisis. Their increasing energy demands require radical sustainable design solutions at the supra-national to regional and regional to local scales. Given today's concerns with climate change and energy future, there is a need for energy autonomous cities. While we are at the verge of twenty-first century, information and energy technology has become the central tenants. Energy future and information technology are quite interlinked. Such link was noticed by many scholars from the late nineteen and early twenty century to present day. Departing from such link, this study presented a potential sustainable path to an ideal energy future by introducing a potential energy assessment model for public space renewable energy infrastructure building on the renowned ecologist Howard 
T. Odum's early theories. To generate local energy economies and create smart learning spaces in addition to the social and ecological function of public space, this study conceptualized public space as an innovation and transformation hub for social and environmental change while considering advancements in renewable energy technologies and their increasing production rates. A transition from fossil fuel to renewable energy is a significant start on the road to future energy autonomy but requires systemic bottom-up and top-down policies and interventions to create a truly sustainable society. The outcome of this study is one such intervention that can inform and advance this critical transition process.

Funding: This research did receive a fee of waive from Energies Journal, many ideas presented here was seeded in my PhD which was funded by Australian Postgraduate Award (APA).

Acknowledgments: I would like to thank Ian Weir, Debra Cushing and Laurie Buys for their support during my $\mathrm{PhD}$ process. I would like to express my deep gratitude to the interviewees and Mcgregor + Coxall team for their time and support. I would also like to thank three reviewers for their constructive feedback helping me to improve this manuscript.

Conflicts of Interest: The author declares no conflict of interest.

\section{References}

1. Droege, P. 100 Per Cent Renewable: Energy Autonomy in Action; Earthscan: London, UK, 2009.

2. Moldan, B.; Janoušková, S.; Hák, T. How to understand and measure environmental sustainability: Indicators and targets. Ecol. Indic. 2012, 17, 4-13. [CrossRef]

3. Byrne, J.; Martinez, C.; Ruggero, C. Relocating Energy in the Social Commons: Ideas for a Sustainable Energy Utility. Bull. Sci. Technol. Soc. 2009, 29, 81-94. [CrossRef]

4. Dincer, I. Renewable energy and sustainable development: A crucial review. Renew. Sustain. Energy Rev. 2000, 4, 157-175. [CrossRef]

5. Cairns, J. Sustainability and specialisation. Ethics Sci. Environ. Politics ESEP 2004, 4, 33-38. [CrossRef]

6. SITES, T.S.S.I. Guidelines and Performance Benchmarks; The American Society of Landscape Architects: Washington, DC, USA; The United States Botanic Garden: Washington, DC, USA; The Lady Bird Johnson Wildflower Center at the University of Texas: Austin, TX, USA, 2009.

7. SITES, T.S.S.I. SITES v2 Rating System For Sustainable Land Design and Development; The American Society of Landscape Architects: Washington, DC, USA; The United States Botanic Garden: Washington, DC, USA; The Lady Bird Johnson Wildflower Center at the University of Texas: Austin, TX, USA, 2014.

8. Ozgun, K.; Weir, I.; Cushing, D. Optimal Electricity Distribution Framework for Public Space: Assessing Renewable Energy Proposals for Freshkills Park, New York City. Sustainability 2015, 7, 3753-3773. [CrossRef]

9. Monoian, E.; Ferry, R. LAGI 2012 Design Guidelines. In Regenerative Infrastructures: Freshkills Park, NYC: Land Art Generator Initiative; Klein, C., Ed.; Prestel: Munich, Germany; London, UK; New York, NY, USA, 2013; p. 30.

10. Khorasany, M.; Azuatalam, D.; Glasgow, R.; Liebman, A.; Razzaghi, R. Transactive Energy Market for Energy Management in Microgrids: The Monash Microgrid Case Study. Energies 2020, 13, 2010. [CrossRef]

11. Silverman, D. Doing Qualitative Research, 4th ed.; SAGE: London, UK; Thousand Oaks, CA, USA, 2013; p. 470.

12. AILA. Ballast Point Park, Birchgrove, Sydney. Available online: http://www.aila.org.au/projects/nsw/ballastpoint/overview.htm (accessed on 1 December 2013).

13. O'Neill, R.; Consultant, Sydney, Australia; Ozgun, K.; Researcher, Sydney, Australia. Personal Communication, 2014.

14. Ozgun, K.; Cushing, D.; Buys, L. Renewable energy distribution in public spaces: Analyzing the case of Ballast Point Park in Sydney, using a triple bottom line approach. Jola J. Landsc. Archit. 2015, 10, 18-31. [CrossRef]

15. Rosen, M.A.; Dincer, I. EXERGY: Energy, Environment and Sustainable Development; Elsevier: Amsterdam, The Netherlands, 2007.

16. Odum, H.T. Self-Organization, Transformity, and Information. Science 1988, 242, 1132. [CrossRef] 
17. Bastianoni, S.; Marchettini, N. Emergy/exergy ratio as a measure of the level of organization of systems. Ecol. Model. 1997, 99, 33-40. [CrossRef]

18. Holmgren, D. Permaculture: Principles E Pathways beyond Sustainability; Holmgren Design Services: Hepburn, Australia, 2002; p. 286.

19. Tilley, D.R.; Howard, T. Odum's contribution to the laws of energy. Ecol. Model. 2004, 178, 121-125. [CrossRef]

20. Odum, H.T. Environmental Accounting; Wiley: Hoboken, NJ, USA, 1996.

21. Odum, H.T.; Odum, E.C. A Prosperous Way Down: Principles and Policies; Univ Pr of Colorado: Boulder, CO, USA, 2008.

22. Miller, K.F. Designs on the Public: The Private Lives of New York's Public Spaces; University of Minnesota Press: Minneapolis, MN, USA, 2007.

23. McDermott, L.; Landscape Architect, Brisbane, Australia; Ozgun, K.; Researcher, Brisbane, Australia. Personal Communication, 2014.

24. Kennedy, T.; Project Manager, Sydney, Australia; Ozgun, K.; Researcher, Sydney, Australia. Personal Communication, 2014.

25. Coxall, P.; Principal Landscape Architect, Sydney, Australia; Ozgun, K.; Researcher, Sydney, Australia. Personal Communication, 2014.

26. Kilbane, S.; Toland, A.; Pham, K. Ballast Point Park; Landscape Architecture Foundation: Washington, DC, USA, 2017. [CrossRef]

27. Alsema, E.A.; Fthenakis, V.M. Photovoltaics Energy Payback Times, Greenhouse Gas Emissions and External Costs: 2004-early 2005 Status. Prog. Photovolt. 2006, 14, 275-280. [CrossRef]

28. Hammond, G.P. Energy and sustainability in a complex world: Reflections on the ideas of Howard, T. Odum. Int. J. Energy Res. 2007, 31, 1105-1130. [CrossRef]

29. Roberts, F. Energy accounting of alternative energy sources. Appl. Energy 1980, 6, 1-20. [CrossRef]

30. Assefa, G.; Frostell, B. Social sustainability and social acceptance in technology assessment: A case study of energy technologies. Technol. Soc. 2007, 29, 63-78. [CrossRef]

31. Rogers, J.; Convery, I.; Simmons, E.; Weatherall, A. Local renewables for Local Places? Attitudes to Renewable Energy and the Role of Communities in Place-based Renewable Energy Development. In Making Sense of Place: Multidisciplinary Perspectives; Convery, I., Corsane, G., Davis, P., Eds.; Boydell \& Brewer: Woodbridge, UK, 2012.

32. Thayer, R.L. Gray World, Green Heart (1994). In Theory in Landscape Architecture: A Reader; Swaffield, S.R., Ed.; University of Pennsylvania Press: Philadelphia, PA, USA, 2002.

33. Huesemann, M.; Huesemann, J. Techno-Fix: Why Technology Won't Save Us Or the Environment; New Society Publishers: New York, NY, USA, 2011.

34. Buys, L.; Vine, D.; Ledwich, G.; Bell, J.; Mengersen, K.; Morris, P.; Lewis, J. A Framework for Understanding and Generating Integrated Solutions for Residential Peak Energy Demand. PLoS ONE 2015, 10, e0121195. [CrossRef]

35. González-Eguino, M. Energy poverty: An overview. Renew. Sustain. Energy Rev. 2015, 47,377-385. [CrossRef]

36. Dóci, G.; Vasileiadou, E.; Petersen, A.C. Exploring the transition potential of renewable energy communities. Futures 2015, 66, 85-95. [CrossRef]

37. Hauber, J.; Ruppert-Winkel, C. Moving towards Energy Self-Sufficiency Based on Renewables: Comparative Case Studies on the Emergence of Regional Processes of Socio-Technical Change in Germany. Sustainability 2012, 4, 491-530. [CrossRef]

38. Scheer, H. Energy Autonomy: The Economic, Social and Technological Case for Renewable Energy; EARTHSCAN: London, UK; Sterling, VA, USA, 2007.

39. Van Timmeren, A.; Zwetsloot, J.; Brezet, H.; Silvester, S. Sustainable Urban Regeneration Based on Energy Balance. Sustainability 2012, 4, 1488-1509. [CrossRef]

40. Wächter, P.; Ornetzeder, M.; Rohracher, H.; Schreuer, A.; Knoflacher, M. Towards a Sustainable Spatial Organization of the Energy System: Backcasting Experiences from Austria. Sustainability 2012, 4, 193-209. [CrossRef]

41. Ilic, D.; Da Silva, P.G.; Karnouskos, S.; Griesemer, M. An energy market for trading electricity in smart grid neighbourhoods. In Proceedings of the Digital Ecosystems Technologies (DEST), 2012 6th IEEE International Conference on, Campione d'Italia, Italy, 18-20 June 2012; pp. 1-6. 
42. Byrne, J.; Taminiau, J. A review of sustainable energy utility and energy service utility concepts and applications: Realizing ecological and social sustainability with a community utility. Wiley Interdiscip. Rev. Energy Environ. 2015. [CrossRef]

43. Houck, J.; Rickerson, W. The sustainable energy utility (SEU) model for energy service delivery. Bull. Sci. Technol. Soc. 2009, 29, 95-107. [CrossRef]

44. Meyer, E.K. Sustaining beauty. The performance of appearance: A manifesto in three parts. J. Landsc. Archit. 2008, 3, 6-23. [CrossRef]

(C) 2020 by the author. Licensee MDPI, Basel, Switzerland. This article is an open access article distributed under the terms and conditions of the Creative Commons Attribution (CC BY) license (http://creativecommons.org/licenses/by/4.0/). 